GASTRIC PHYSIOLOGY

\title{
Ghrelin treatment reverses the reduction in weight gain and body fat in gastrectomised mice
}

\author{
C Dornonville de la Cour, A Lindqvist, E Egecioglu, Y C L Tung, V Surve, C Ohlsson, \\ J-O Jansson, C Erlanson-Albertsson, S L Dickson, R Håkanson
}

Gut 2005;54:907-913. doi: 10.1136/gut.2004.058578

See end of article for
authors' affiliations
$\ldots \ldots \ldots \ldots \ldots \ldots \ldots \ldots . \ldots . \ldots$
Correspondence to:
Professor R Håkanson,
Department of
Pharmacology, Institute of
Physiological Sciences,
University of Lund, BMC
F13, S-221-84 Lund,
Sweden; rolf.hakanson@
farm.lu.se
Revised version received
13 March 2005
Accepted for publication
22 March 2005
Published Online First
21 April 2004
Background and aims: The gastric hormone ghrelin has been reported to stimulate food intake, increase weight gain, and cause obesity but its precise physiological role remains unclear. We investigated the long term effects of gastrectomy evoked ghrelin deficiency and of daily ghrelin injections on daily food intake, body weight, fat mass, lean body mass, and bone mass in mice.

Methods: Ghrelin was given by subcutaneous injections ( $12 \mathrm{nmol} /$ mouse once daily) for eight weeks to young female mice subjected to gastrectomy or sham operation one week previously.

Results: Gastrectomy reduced plasma concentrations of total ghrelin (octanoylated and des-octanoylated) and active (octanoylated) ghrelin by $\sim 80 \%$. Immediately after injection of ghrelin, the plasma concentration was supraphysiological and was still elevated 16 hours later. Daily food intake was not affected by either gastrectomy or ghrelin treatment. The effect of ghrelin on meal initiation was not studied. At the end point of the study, mean body weight was $15 \%$ lower in gastrectomised mice than in sham operated mice $(p<0.001)$; daily ghrelin injections for eight weeks partially prevented this weight loss. In sham operated mice, ghrelin had no effect on body weight. The weight of fat was reduced in gastrectomised mice ( $-30 \% ; p<0.01)$. This effect was reversed by ghrelin, enhancing the weight of fat in sham operated mice also ( $+20 \% ; p<0.05)$. Gastrectomy reduced lean body mass $(-10 \% ; p<0.01)$ and bone mass $(-20 \% ; p<0.001)$ compared with sham operated mice. Ghrelin replacement prevented the gastrectomy induced decrease in lean body mass but did not affect bone. In sham operated mice, ghrelin affected neither of these two parameters.

Conclusions: Ghrelin replacement partially reversed the gastrectomy induced reduction in body weight, lean body mass, and body fat but not in bone mass. In sham operated mice, ghrelin only increased fat mass. Our results suggest that ghrelin is mainly concerned with the control of fat metabolism and that ghrelin replacement therapy may alleviate the weight loss associated with gastrectomy.
$\mathrm{T}$ he peptide hormone ghrelin is produced by A-like cells in the acid producing part of the stomach but small amounts also occur further down in the digestive tract and in the pancreas. ${ }^{1-4}$ In addition, there are reports of ghrelin immunoreactive neurones in the hypothalamus. ${ }^{5-7}$ Ghrelin was discovered by virtue of its ability to stimulate $\mathrm{Ca}^{2+}$ entry in a cell line expressing the growth hormone secretagogue (GHS) receptor. Subsequently, ghrelin was shown to release growth hormone $(\mathrm{GH})$ from somatotrophs in the adenohypophysis. ${ }^{5}$ Indeed, a ghrelin challenge is known to raise serum concentration of GH. ${ }^{5-10}$

According to a number of reports, administration of pharmacological doses of ghrelin to intact animals increases food intake, induces weight gain, and causes obesity. ${ }^{11-16}$ The orexigenic and body fat promoting properties of ghrelin and GHS are thought to be independent of GH and mediated by the hypothalamic neuropeptide $\mathrm{Y}$ and agouti related protein systems. ${ }^{11}{ }^{13} 15^{17-19}$ As noted above, the effects of pharmacological ghrelin treatment are well documented but the role of endogenous ghrelin is by comparison poorly understood. It has been reported recently that knockout of either the ghrelin gene or the ghrelin receptor gene exerts no or minor effects on body growth and body composition. ${ }^{20-22}$ However, the lack of phenotypic changes in knockout mice may reflect compensatory mechanisms, manifested already during embryonic development, a stage characterised by great plasticity. This problem may be avoided by depleting animals of ghrelin during adult life.

In humans, gastrectomy $(\mathrm{Gx})$ results in loss of body weight of about $10 \%$ within the first six months after surgery, mainly due to reduced body fat. ${ }^{23}$ In addition, Gx patients often complain of fatigue and loss of appetite and several reports describe impaired bone quality (osteopenia/osteomalacia). ${ }^{24-28}$ At present there is no satisfactory treatment for any of these symptoms. In rats, Gx is associated with bone loss (compared with controls) while body weight is affected marginally, if at all. ${ }^{29-31}$ On the whole, the effects of Gx on food intake and body composition (other than bone) have been poorly documented in rodents.

In rats and humans, more than $80 \%$ of circulating ghrelin is lost following surgical removal of the glandular stomach or the acid producing part of the stomach ${ }^{232}$ and we predict a similar reduction in Gx mice. The postulated adipogenic and anabolic effects of ghrelin prompted us to investigate whether the effects of Gx can be reversed by long term ghrelin treatment in mice.

\section{METHODS}

\section{Chemicals}

In all, $55 \mathrm{mg}$ of octanoylated ghrelin-28 was made available for the study through collection of ghrelin from three different sources. During the first four weeks of the study, we used rat ghrelin, kindly donated by Professor Chizuka Yanaihara at the Yanaihara Institute, Shizuoka, Japan. In the following two weeks mice were treated with rat ghrelin from Innovagen, Lund, Sweden (custom synthesis), and

Abbreviations: Gx, gastrectomy; $\mathrm{GH}$, growth hormone; GHS, growth hormone secretagogue; BMD, bone mineral density; IGF-1, insulin-like growth factor 1 
subsequently (the two last weeks) they received human ghrelin, kindly provided by Dr Matthias Tschöp (University of Cincinnati, Cincinnati, Ohio, USA). Each batch of ghrelin was tested for purity by high pressure liquid chromatography and for bioactivity by measuring the effects of a single subcutaneous injection of $10 \mu \mathrm{g}(3 \mathrm{nmol})$ ghrelin on gastric emptying $^{33}$ and/or rise in plasma GH concentration. Ghrelin was dissolved in $0.9 \%$ saline (sterile); fresh solutions were prepared daily.

\section{Animals}

Female NMRI mice (aged 8-9 weeks) were obtained from B\&K (Sollentuna, Sweden). They were kept in groups of two or three in plastic cages in a temperature controlled environment $\left(21^{\circ} \mathrm{C}\right)$ on a 12 hour light/dark cycle, with free access to standard food pellets (Lactamin, Vadstena, Sweden) and tap water. They were allowed to acclimatise for a week before surgery. At the time of surgery body weight was approximately $33 \mathrm{~g}$. Body weights were determined every week thereafter. The experiments were approved by the local animal welfare committee, Lund, Sweden.

\section{Selection of the ghrelin dose}

In a pilot study, intact mice received $12 \mathrm{nmol}(\mathrm{n}=6)$ or $24 \mathrm{nmol}(\mathrm{n}=6)$ of ghrelin in $0.9 \%$ saline by a subcutaneous bolus injection in the neck (corresponding to 400 and $800 \mathrm{nmol} / \mathrm{kg}$, respectively). Small blood samples $(25 \mu \mathrm{l})$ were drawn repeatedly by retro-orbital venepuncture before (time 0 ) and 15, 60, 120, 240, and 300 minutes after injection of ghrelin. The ghrelin doses tested were selected based on the report of Tschöp et al $(2.4 \mu \mathrm{mol} / \mathrm{kg}) .{ }^{12}$ After demonstrating that both 12 and $24 \mathrm{nmol}$ of ghrelin generated blood levels in excess of physiological concentrations for more than
16 hours after injection, we selected a dose of $12 \mathrm{nmol}$. The purpose of the study was to replace ghrelin that was lost after Gx using doses that generated near physiological plasma concentrations; there was no intent to induce sustained supraphysiological plasma concentrations of ghrelin. The dose of $12 \mathrm{nmol}$ was found to satisfy these requirements.

\section{Surgery}

Mice were randomly subjected to Gx (26 mice) or sham operation (22 mice). They were anaesthetised with an intraperitoneal injection of a mixture of fluanisone/fentanyl/midazolam (15/0.5/7.5 mg/kg). Gastric surgery was performed through a midline abdominal incision with clean but not sterile instruments. No antibiotics were used. Gx was carried out by resection of the stomach, followed by anastomosis of the oesophagus with the duodenum, end to end. The procedure of Gx includes bilateral subdiaphragmatic vagotomy. Two of the $26 \mathrm{Gx}$ mice died during the first week after surgery (that is, before ghrelin treatment started). Sham operation consisted of a midline abdominal incision and gentle manipulation of the stomach. There was no mortality in this group. Mice were allowed to recover from surgery for about a week before starting treatment with ghrelin or vehicle.

\section{Study design}

The study comprised 24 Gx mice and 22 sham operated mice. Twelve Gx mice and 12 sham operated mice received a subcutaneous dose of ghrelin $(12 \mathrm{nmol})$ daily for eight weeks. Twelve Gx mice and 10 sham operated mice received daily injections of saline for eight weeks. On the first 14 days, injections were given in the morning $(8-9$ am) and subsequent injections were made in the afternoon (5-6 pm).
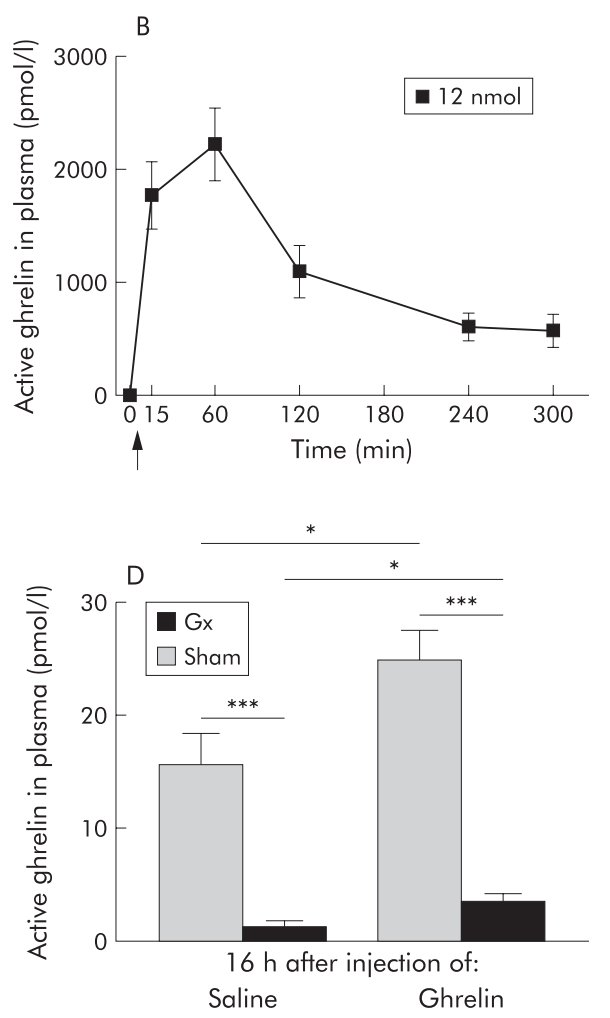

Figure 1 Plasma concentrations of total and active (octanoylated) ghrelin. A single subcutaneous injection (arrow) of either 12 or $24 \mathrm{nmol}$ of ghrelin to intact mice promptly raised plasma concentrations of total (A) and active (B) ghrelin ( $n=6$ in each group). Plasma concentrations of total and active ghrelin were low following gastrectomy (Gx) compared with sham operation in mice. Concentrations of total ghrelin (C) and active (D) ghrelin remained elevated 16 hours after injection of 12 nmol of ghrelin after sham operation or gastrectomy in mice. Values are means $($ SEM); $n=10-12$. ${ }^{*} p<0.05,{ }^{* *} p<0.01,{ }^{* *} p<0.001$. 

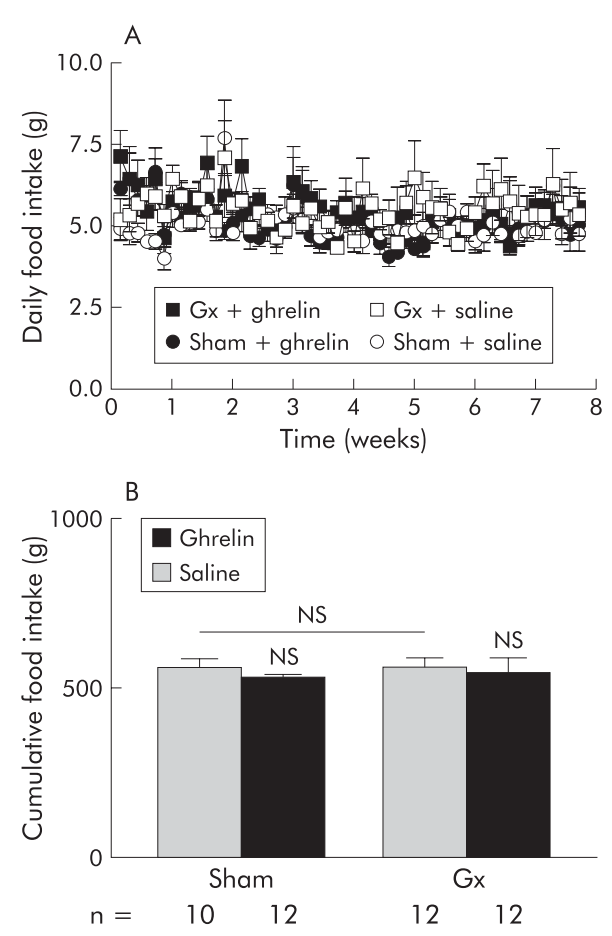

Figure 2 Food intake after sham operation or gastrectomy $(G x)$ in mice receiving daily injections of either saline or ghrelin $(12 \mathrm{nmol}$ daily subcutaneous (y) for eight weeks. There was no statistically significant difference in daily food intake ( $\mathrm{g} /$ animal) between the different groups at any time point (A) or in cumulative food intake ( $\mathrm{g} /$ animal) over eight weeks between the groups (B). Values are means (SEM) ( $n=$ number of mice).

Daily food intake in these animals was calculated as the difference between the amount of food given and the amount of food that remained after 24 hours. Cumulative body weight gain was based on weekly determinations of body weights and expressed as body weight minus weight at the start of ghrelin treatment for each mouse. After eight weeks of treatment with ghrelin or saline, mice were killed by decapitation (16-18 hours after the last injection). Blood was collected from the neck and plasma prepared (see below). White adipose tissue (mesenteric, retroperitoneal, parametrial, and inguinal) was dissected out and weighed. Lean tissue and bone mineral density (BMD) were assessed (whole mouse) by dual energy $x$ ray absorptiometry (DEXA; PIXImus, Lunar Corporation, Madison, Michigan, USA). Femurs were collected and their lengths measured after which they were incinerated for 24 hours at $600^{\circ} \mathrm{C}$. Ash weight was determined.

\section{Measurement of circulating ghrelin and insulin-like growth factor 1 (IGF-1)}

Concentrations of circulating ghrelin and IGF-1 were determined in plasma from animals at sacrifice (end point analysis). Blood samples were collected and plasma prepared according to the respective manufacturer's protocol.

\section{Total ghrelin}

Immunoreactive ghrelin was measured in 5-20 $\mu \mathrm{l}$ of plasma using a commercial radioimmunoassay kit (Phoenix Pharmaceuticals, Belmont, California, USA) with an antiserum raised against acylated human ghrelin; ${ }^{125}$ I labelled ghrelin-28 was used as tracer and rat ghrelin-28 as standard. The antiserum recognises both octanoylated and des-octanoylated ghrelin-28 but does not recognise des-Gln ${ }^{14}$ ghrelin. Plasma concentrations were expressed as pmol equivalents of

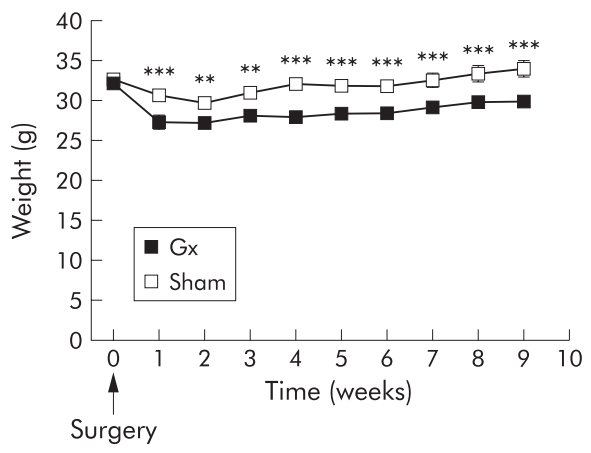

Figure 3 Body weight at different times before (time 0) and after sham operation or gastrectomy (Gx) (arrow indicates surgery). After nine weeks, mean body weight of Gx mice was $15 \%$ lower than that of sham operated mice. Values are means (SEM); $n=10-12 .{ }^{* *} p<0.01$, ${ }^{* * *} p<0.001$.

rat ghrelin-28 per litre. The detection limit for total ghrelin is $12 \mathrm{fmol} / \mathrm{l}$. Intra- and interassay variation was 3\% and $8 \%$, respectively.

\section{Active ghrelin}

Active (octanoylated) ghrelin was determined in $50 \mu \mathrm{l}$ of plasma using an enzyme linked immunosorbent assay kit (Linco Research, St Charles, Missouri, USA). The antiserum does not recognise des-octanoylated ghrelin. The detection limit for active ghrelin is $1 \mathrm{pmol} / \mathrm{l}$. Intra- and inter assay variation was $3 \%$ and $4 \%$, respectively.

\section{IGF-1}

Plasma IGF-1 was measured in $10 \mu \mathrm{l}$ of plasma with a radioimmunoassay kit from Mediagnost (Reutlingen, Germany). The sensitivity of this assay is $0.02 \mathrm{nmol} / \mathrm{l}$.

\section{Statistical analysis}

Values are expressed as means (SEM). Differences were analysed statistically using the Student's unpaired $t$ test or by analysis of variance (ANOVA) followed by Tukey-Kramer's test, where appropriate (continuous measurements). A p value of $<0.05$ was considered statistically significant. The half-life of ghrelin in the circulation was calculated based on the curve showing plasma concentrations following a single ghrelin injection (fig 1) (GraphPad Prism version 3.0; GraphPad Software, San Diego, California, USA). Correlation between total and active ghrelin was calculated by Pearsons's linear regression test.

\section{RESULTS}

\section{Plasma concentrations of ghrelin}

A single subcutaneous injection of either 12 or $24 \mathrm{nmol}$ of ghrelin to intact mice promptly raised the circulating concentration of total (active octanoylated and inactive des-octanoylated) ghrelin, with a peak value after 15-60 minutes (fig 1A). Five hours after injection of either dose, circulating total ghrelin concentration was markedly decreased compared with the peak value but was still higher than the ghrelin concentration before injection ( $12 \mathrm{nmol}$ dose: 0.6 (0.07) v $2.1(0.4) \mathrm{nmol} / \mathrm{l} ; 24 \mathrm{nmol}$ dose: $0.8(0.09) v 7.1(2.5) \mathrm{nmol} / \mathrm{l})$. Plasma concentrations of active (octanoylated) ghrelin showed a similar time course (fig 1B); five hours after injection of $12 \mathrm{nmol}$ ghrelin, concentrations were still much higher than before injection (19.5 (1.6) $v 570$ (149) pmol/l). The half lives of total and active ghrelin were calculated from the data in fig $1 \mathrm{~A}$ and $1 \mathrm{~B}$ and found to be 85 and 105 minutes, respectively.

Circulating concentrations of total and active ghrelin were greatly reduced by Gx (measured eight weeks after 

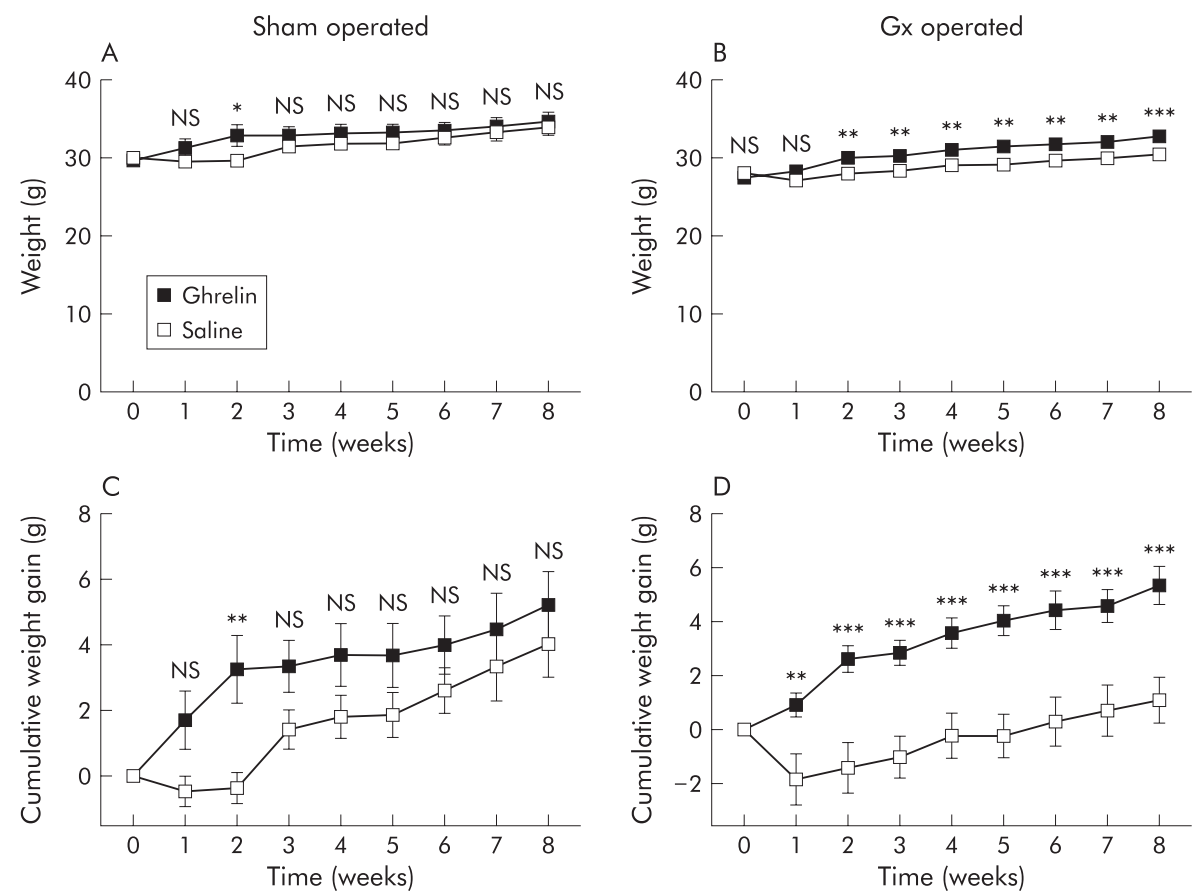

Figure 4 Body weight development after (A) sham operation or (B) gastrectomy (Gx) in mice receiving daily injections of saline or ghrelin (12 nmol subcutaneously) for eight weeks (starting at time 0). (A, B) Ghrelin increased body weight in Gx mice (8\%) but not in sham operated mice. Ghrelin increased the cumulative weight gain in Gx mice (D) but not that of sham operated mice (C). Values are means (SEM); $n=10-12$. Vertical bars are invisible at times because SEM values are small. ${ }^{*} p<0.05,{ }^{* *} p<0.01,{ }^{* * *} p<0.001$.

operation) (fig 1C, 1D). Sixteen hours after injection of ghrelin ( $12 \mathrm{nmol}$ ), plasma concentrations (total and active ghrelin) remained elevated compared with after saline injection in both Gx and sham operated animals (fig lC, 1D). There was a positive correlation between levels of circulating total and active ghrelin $(r=0.54 ; \mathrm{p}<0.008, \mathrm{n}=6)$.

\section{Food intake}

Daily food intake, expressed as g/individual, did not differ between Gx and sham operated mice, and there was no difference in daily food intake between mice receiving a daily dose of ghrelin and those receiving saline (fig 2A). Daily food intake, expressed as $\mathrm{g} / \mathrm{g}$ body weight, did not differ between the groups: 9.7 (0.6) for Gx mice, 8.8 (0.7) for sham operated mice, $8.9(0.7)$ in ghrelin treated Gx mice, and $7.9(0.4)$ in ghrelin treated sham operated mice $(\mathrm{p}>0.05)$. Cumulative food intake, expressed as g/individual over time, was similar in sham operated and Gx mice, and ghrelin treatment did not affect cumulative food intake in either sham operated $(\mathrm{p}=0.28)$ or $\mathrm{Gx}(\mathrm{p}=0.78)$ mice (fig $2 \mathrm{~B})$.

\section{Weight gain}

Mean body weight was lower in GX mice three weeks after surgery, continuing until nine weeks after surgery, than in sham operated mice. Nine weeks after surgery, body weight of $\mathrm{Gx}$ mice was $15 \%$ lower than in sham operated controls $(p<0.001)$ (fig 3). Daily injections of ghrelin to Gx mice raised body weight (compared with saline treated Gx mice); the relative weight increase was $8 \%$ after eight weeks of treatment $(p<0.001)$ (fig $4 \mathrm{~B})$. Most of the difference in cumulative body weight gain between ghrelin and saline treated Gx animals occurred during the first two weeks of treatment (fig 4D). Cumulative body weight gain in Gx mice was increased by eight weeks of ghrelin treatment compared with Gx mice receiving saline $(5.4(0.7) \quad v \quad 1.1 \quad(0.8) \mathrm{g}$; $\mathrm{p}<0.001$ ) (fig 4D). In contrast, body weight and cumulative body weight gain in sham operated mice were only significantly affected by ghrelin two weeks after initiation of treatment and this difference diminished with time (fig 4A, C). Ghrelin did not affect plasma levels of GH dependent IGF-1 or femur length in either Gx or sham operated mice $(\mathrm{p}>0.05)$ (table 1$)$.

\section{Body composition \\ Fat depots}

Gx reduced the total weight of four different fat depots by approximately $30 \%(\mathrm{p}<0.01)$ compared with sham operation. Daily administration of ghrelin normalised the total amount of fat in Gx mice ( $\mathrm{p}=0.95 ; \mathrm{Gx}+$ ghrelin $v$ sham+saline) and raised it by $20 \%(p<0.05)$ in sham operated animals (fig $5 A$ ).

Table 1 Lack of effect of ghrelin (versus saline) on femur bone length and plasma insulinlike growth factor 1 (IGF-1) concentration after sham operation or gastrectomy (Gx) in mice

\begin{tabular}{lllllll}
\hline & Sham+saline & Sham+ghrelin & $\mathbf{p}$ Value & Gx+saline & Gx+ghrelin & p Value \\
\hline Length of femur (mm) & $17.3(0.2)$ & $16.9(0.2)$ & 0.30 & $17.0(0.1)$ & $16.9(0.1)$ & 0.47 \\
Plasma IGF-1 (nmol/I) & $53(3.7)$ & $54.1(1.5)$ & 0.78 & $52.1(2.2)$ & $53.8(2.5)$ & 0.56 \\
\hline
\end{tabular}

Duration of the study was eight weeks.

Values are means (SEM); $\mathrm{n}=10-12$

$p$ values refer to differences between saline and ghrelin treatments. 

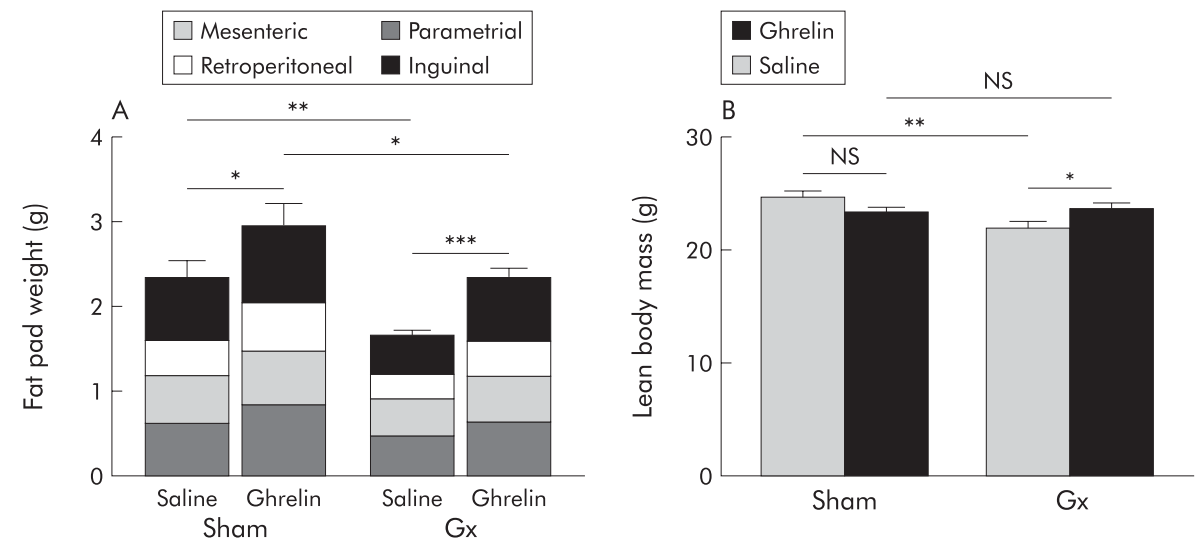

Figure 5 Effects of gastrectomy (Gx) and/or daily administration of ghrelin (12 nmol subcutaneously) for eight weeks on body composition. (A) Gx reduced the amount of fat $(-30 \%)$; this effect was prevented by ghrelin.

Administration of ghrelin also increased the amount of fat in sham operated mice (20\%). (B) Gx reduced lean body mass $(-10 \%)$ while administration of ghrelin reversed the effect. There was no statistically significant difference in lean body mass between the two groups of sham operated mice receiving either saline or ghrelin (C) Gx reduced bone mineral density (BMD) (-20\%); ghrelin treatment had no effect. (D) Gx reduced femur ash weight $(-20 \%)$. Daily ghrelin administration did not affect the bone of either sham operated or Gx mice. Values are means (SEM); $\mathrm{n}=10-12$
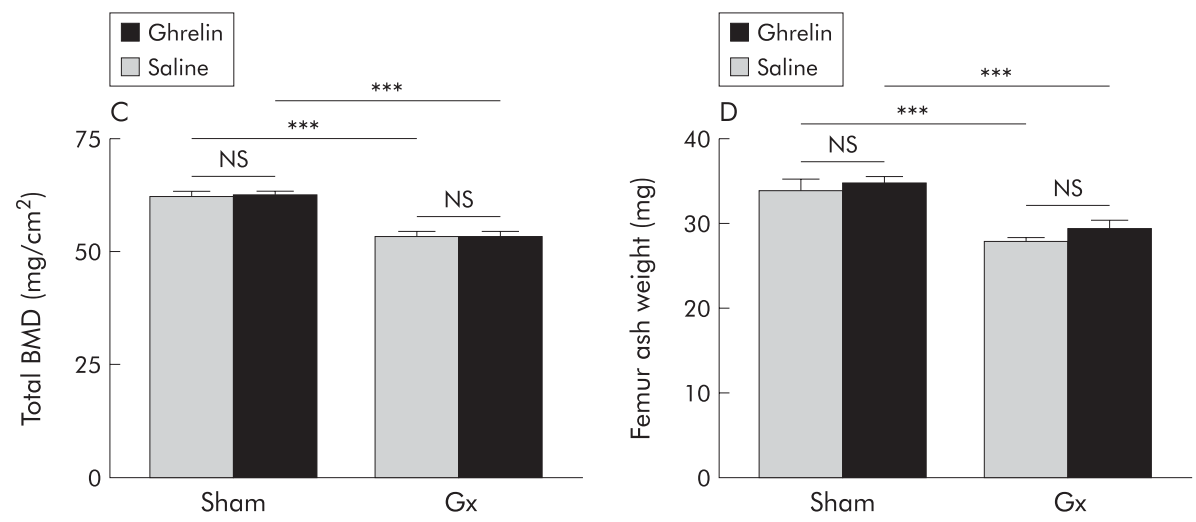
${ }^{*} p<0.05,{ }^{* *} p<0.01,{ }^{* * *} p<0.001$.

The effect of ghrelin on individual fat depots was not statistically significant (table 2).

\section{Lean body mass}

Gx reduced the amount of lean tissue $(-10 \% ; \mathrm{p}<0.01)$ compared with sham operation. Daily administration of ghrelin increased the amount of lean tissue in Gx mice $(8 \% ; \mathrm{p}<0.05)$ but had no effect in sham operated mice $(\mathrm{p}>0.05)$ (fig 5B)

\section{Bone mass}

Total BMD and bone ash weight of the femur was lower in Gx mice than in sham operated mice $(-20 \%$; $<<0.001)$. Daily administration of ghrelin failed to affect BMD and femur ash weight in either $\mathrm{Gx}$ or sham operated mice (fig 5C, D).

\section{DISCUSSION}

Gx decreased body weight, body fat mass, lean body mass, and bone mass, and was accompanied by greatly reduced circulating concentrations of total and active ghrelin ( $~ 80 \%$ decrease), raising the possibility that the effects of $\mathrm{Gx}$ on body composition are due to hypoghrelinaemia. Ghrelin has been put forward as a signal stimulating food intake, ${ }^{11} 13-16$ body weight gain, ${ }^{10-12}$ and fat deposition. ${ }^{12}{ }^{14}$ In the present study, ghrelin increased body fat but had no effect on daily food intake, weight gain, lean body mass, or bone mass in sham operated mice. In Gx mice, however, daily ghrelin injections, resulting in hyperghrelinaemia, partly prevented the reduction in body weight, lean body mass, and fat mass without affecting daily food intake and bone mass. The hypothesis originally put forward by Cummings and colleagues $^{34}$ that ghrelin deficiency contributes to the loss of fat in patients after gastric bypass surgery is in line with our results suggesting that ghrelin helps retain body fat (and possibly lean body mass) in mice. The previously reported absence of deficiency symptoms in knockout mice, lacking ghrelin or ghrelin receptors, ${ }^{20-22}$ could be due to compensatory mechanisms during development. Further studies are needed to clarify the role of ghrelin in the regulation of body composition.

Our results raise the possibility that ghrelin replacement therapy can reverse some of the symptoms associated with Gx in humans. Therapeutic Gx in humans is associated with osteopathy, loss of body weight and body fat, as well as

Table 2 Effect of ghrelin (versus saline) on the weight of individual fat depots after sham operation or gastrectomy (Gx) in mice

\begin{tabular}{lllllll}
\hline Fat depot & Sham+saline & Sham+ghrelin & $\mathbf{p}$ Value & $\mathbf{G x + \text { saline }}$ & $\mathbf{G x + g h r e l i n}$ & $\mathbf{p}$ Value \\
\hline Mesenteric & $0.5(0.06)$ & $0.6(0.07)$ & 0.072 & $0.4(0.04)$ & $0.5(0.04)$ & 0.093 \\
Retroperitoneal & $0.4(0.08)$ & $0.6(0.1)$ & 0.40 & $0.3(0.04)$ & $0.4(0.04)$ & 0.12 \\
Parametrial & $0.6(0.1)$ & $0.8(0.2)$ & 0.22 & $0.5(0.07)$ & $0.7(0.08)$ & 0.36 \\
Inguinal & $0.7(0.2)$ & $0.9(0.2)$ & 0.02 & $0.5(0.06)$ & $0.8(0.1)$ & 0.60 \\
\hline
\end{tabular}

Duration of the study was eight weeks.

Values are mean (SEM); $\mathrm{n}=10-12$.

$p$ values refer to differences between saline and ghrelin treatments. 
fatigue and decreased quality of life. ${ }^{23-28}$ At present, there are no generally accepted treatments for the catabolic effects of Gx. In mice, Gx resulted in a reduction in body weight and in the amount of lean tissue, bone, and fat compared with sham operation. Therefore, Gx mice may serve as a model for the clinical symptoms associated with $\mathrm{Gx}$ in patients although $\mathrm{Gx}$ mice continued to grow (except during the first two postoperative weeks) and hence cannot be described as catabolic.

The ghrelin induced weight gain in Gx mice relative to saline injected Gx mice was particularly apparent during the first two weeks of treatment, after which time most of the gastrectomy evoked weight loss had been reversed. Previous studies have shown that the stimulatory effect of ghrelin or ghrelin analogues on body weight in intact mice plateaus after approximately 2-6 weeks, ${ }^{12}{ }^{19}$ possibly because the animals have reached a new set point for body weight at that time.

The present finding that ghrelin treatment enhanced body weight and body fat mass in Gx mice (that were also vagotomised) is interesting in view of the fact that subdiaphragmatic vagotomy per se has been reported to prevent the meal initiating effect of ghrelin. ${ }^{1135}$ Conceivably, vagotomy impairs ghrelin stimulated meal initiation but not the long term effects of ghrelin on body fat. In the present study we did not investigate the effects of ghrelin in animals that were vagotomised only, but the fact that ghrelin was more effective in Gx (and vagotomised) mice than in vagally intact mice suggests that vagotomy does not prevent ghrelin from stimulating fat deposition.

The simplest interpretation of our data seems to be that endogenous ghrelin contributes to maintain body fat (and indirectly body weight). Low levels of circulating ghrelin in Gx mice appeared to contribute to loss of body fat and body weight, as these effects were alleviated by ghrelin treatment. Although ghrelin increased body fat in both Gx and sham operated mice, ghrelin affected body weight in Gx mice but not in sham operated mice. Tschöp and colleagues ${ }^{12}$ observed an effect of ghrelin on both body weight and body fat in intact mice; the ghrelin dose was six times higher than that in the present study $(2.4 v 0.4 \mu \mathrm{mol} / \mathrm{kg})$. However, the fact that ghrelin treatment in this study resulted in substantially higher than normal blood levels of ghrelin for a large part of the day would seem to disagree with the interpretation that our treatment protocol was suboptimal. However, we could only partly reverse the $\mathrm{Gx}$ induced decrease in body weight. This could be due to the fact that Gx causes defects other than ghrelin deficiency, such as loss of ability to ingest large amounts of food or loss of other, as yet unidentified, gastric hormones. In any case, the Gx model may be complementary to ghrelin and ghrelin receptor knockout models $\mathrm{s}^{20-22}$ by providing information about the effects of hypoghrelinaemia in adult animals.

The plasma concentration of active (octanoylated) ghrelin was much lower than that of total (octanoylated+desoctanoylated) ghrelin. The ratio of active versus total ghrelin was similar in different individuals and in different experimental groups, in line with other studies. ${ }^{35}$ This finding increases the likelihood that our measurements of active ghrelin reflect true values, assuming that the concentration of total ghrelin is proportional to that of active ghrelin.

Ghrelin did not stimulate daily food intake (see also Tschöp and colleagues ${ }^{12}$ ) in either intact or Gx mice, which is in line with the view that the postulated stimulatory effect of ghrelin is restricted to the first few hours after injection of the hormone (meal initiation). ${ }^{13}$ Our observation that ghrelin increases body weight and body fat in Gx mice without affecting daily food intake could suggest that rather than causing hyperphagia, ghrelin suppresses energy metabolism, but further studies are needed to confirm this. However, this is in line with the view of Tschöp and colleagues ${ }^{12}$ that ghrelin exerts long term effects on energy balance in intact mice by increasing the respiratory quotient, suggesting increased utilisation of carbohydrates and decreased utilisation of fat as an energy source. Interestingly, Wortley and colleagues $^{22}$ recently showed that ghrelin knockout mice had unchanged food intake (but displayed a decreased respiratory quotient on a high fat diet), supporting the notion that the long term effects of endogenous ghrelin on body composition are mediated by changes in fuel preference rather than in food intake. In humans, the results of several studies have indicated a negative correlation between circulating ghrelin levels and energy expenditure. ${ }^{36} 37$

Our finding that administration of ghrelin increased body fat mass (despite the well known lipolytic effect of GH) without affecting daily food intake, femur length, or plasma IGF-1 suggests that the effect does not reflect an action in the hypothalamus-hypophysis causing GH mobilisation. Neither do our results support the view that circulating ghrelin acts on fat (and body weight) via the vagus (since Gx mice responded to ghrelin). Hence the site of the lipogenic action of ghrelin is not known. Although AgRP/NPY neurones of the arcuate nucleus ${ }^{17}{ }^{38}$ represent a possible target for circulating ghrelin, it is perhaps more likely that ghrelin acts by a peripheral mechanism. Indeed, ghrelin has been suggested to exert lipogenic effects directly on adipocytes. ${ }^{39}{ }^{40} \mathrm{Gx}$ does not affect plasma concentrations of glucose, insulin, or glucagon in freely fed mice. ${ }^{41}$ However, Gx affects pancreatic islet function in that Gx mice display an impaired insulin (and glucagon) response to oral as well as intravenous glucose and reduced glucose tolerance. ${ }^{41}$ Although there were no abnormalities in serum lipids in Gx mice, ${ }^{41}$ it cannot be excluded that the Gx evoked impairment of pancreatic islet function may contribute to loss of fat. Within the physiological plasma concentration range, ghrelin seems to have modest effects on circulating levels of insulin and glucose. ${ }^{42}$

Gx decreased bone mineral density and bone ash weight of the femur compared with sham operated mice. This is in line with earlier studies of rats, showing that the acid producing part of the stomach is required to maintain a normal skeleton. ${ }^{29-31}{ }^{43-47}$ It has been suggested that as yet unidentified hormones in the oxyntic mucosa promote the growth and development of trabecular bone by ensuring proper utilisation of circulating $\mathrm{Ca}^{2+}{ }^{43}$ Also, GH is thought to be important for normal bone growth..$^{48}$ Therefore, ghrelin, being a powerful GH secretagogue, is a candidate for the proposed bone preserving hormone in the stomach. However, as ghrelin treatment did not affect bone in sham operated mice and did not reverse the effect of Gx on bone, the present results do not support the idea that ghrelin deficiency can explain the Gx evoked osteopenia.

In conclusion, our findings suggest that ghrelin treatment can reverse the reduction in body fat and body weight observed in Gx mice. These results are in line with a physiological role of ghrelin in the regulation of body composition (notably fat), raising the possibility that ghrelin replacement therapy may alleviate some of the clinical symptoms of $\mathrm{Gx}$ in humans.

\section{ACKNOWLEDGEMENTS}

We are grateful to Dr Peter Höglund, Lund University Hospital, for statistical guidance, and Britt Carlsson and Anna Themner-Persson for expert technical assistance. This study was supported by grants from the Swedish Research Council (04x-1007, 04x-14610 and 5212003-5116), the A Påhlsson Foundation, the Novo Nordisk Foundation, the Frederik Paulsen Foundation, the Medical Faculty of Lund University, the 6th framework (LSHM-CT-2003-503041), Swedish Medical Research Council (2003-04-14610-01A), and the Medical Research Council (UK). 


\section{Authors' affiliations}

C Dornonville de la Cour, V Surve, R Håkanson, Department of Pharmacology, Institute of Physiological Sciences, University of Lund, Lund, Sweden

A Lindqvist, C Erlanson-Albertsson, Department of Cell and Molecular Biology, University of Lund, Lund, Sweden

E Egecioglu, Department of Physiology, Gothenburg University, Gothenburg, Sweden

Y C L Tung, Department of Physiology, University of Cambridge, Cambridge, UK

C Ohlsson, J-O Jansson, Research Centre for Endocrinology and Metabolism, Sahlgrenska University Hospital, Gothenburg, Sweden S L Dickson, Department of Physiology, Gothenburg University, Gothenburg, Sweden, and Department of Physiology, University of Cambridge, Cambridge, UK

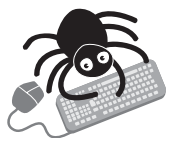

Conflict of interest: declared (the declaration can be viewed on the Gut website at http://www.gut.com/ supplemental)

\section{REFERENCES}

1 Date $Y$, Kojima $M$, Hosoda H, et al. Ghrelin, a novel growth hormonereleasing acylated peptide, is synthesized in a distinct endocrine cell type in the gastrointestinal tracts of rats and humans. Endocrinology 2000;141:4255-61

2 Dornonville de la Cour C, Biörkqvist $M$, Sandvik AK, et al. A-like cells in the rat stomach contain ghrelin and do not operate under gastrin control. Regul Pept 2001;99:141-50.

3 Rindi G, Necchi V, Savio A, et al. Characterisation of gastric ghrelin cells in man and other mammals: studies in adult and fetal tissues. Histochem Cell Biol 2002; 117:511-19.

4 Hosoda $\mathrm{H}$, Kojima $M$, Matsuo $H$, et al. Ghrelin and des-acyl ghrelin: two major forms of rat ghrelin peptide in gastrointestinal tissue. Biochem Biophys Res Commun 2000;279:909-13.

5 Kojima M, Hosoda H, Date Y, et al. Ghrelin is a growth-hormone-releasing acylated peptide from stomach. Nature 1999;402:656-60.

6 Lu S, Guan JL, Wang QP, et al. Immunocytochemical observation of ghrelincontaining neurons in the rat arcuate nucleus. Neurosci Lett 2002;321:157-60.

7 Cowley MA, Smith RG, Diano S, et al. The distribution and mechanism of action of ghrelin in the CNS demonstrates a novel hypothalamic circuit regulating energy homeostasis. Neuron 2003;37:649-61.

8 Seoane LM, Tovar S, Baldelli R, et al. Ghrelin elicits a marked stimulatory effect on GH secretion in freely-moving rats. Eur J Endocrinol 2000;143:R7-9.

9 Takaya K, Ariyasu H, Kanamoto N, et al. Ghrelin strongly stimulates growth hormone release in humans. J Clin Endocrinol Metab 2000;85:4908-1 1.

10 Nagaya N, Uematsu M, Kojima M, et al. Chronic administration of ghrelin improves left ventricular dysfunction and attenuates development of cardiac cachexia in rats with heart failure. Circulation 2001;104:1430-5.

11 Asakawa A, Invi A, Kaga T, et al. Ghrelin is an appetite-stimulatory signal from stomach with structural resemblance to motilin. Gastroenterology 2001; 120:337-45.

12 Tschöp M, Smiley DL, Heiman ML. Ghrelin induces adiposity in rodents. Nature 2000;407:908-13.

13 Wren AM, Small CJ, Ward HL, et al. The novel hypothalamic peptide ghrelin stimulates food intake and growth hormone secretion. Endocrinology 2000; 141:4325-8.

14 Wren AM, Small CJ, Abbott CR, et al. Ghrelin causes hyperphagia and obesity in rats. Diabetes 2001;50:2540-7.

15 Kamegai J, Tamura H, Shimizu T, et al. Chronic central infusion of ghrelin increases hypothalamic neuropeptide $Y$ and Agouti-related protein mRNA levels and body weight in rats. Diabetes 2001;50:2438-43.

16 Nakazato M, Murakami N, Date Y, et al. A role for ghrelin in the central regulation of feeding. Nature 2001;409:194-8.

17 Dickson SL, Luckman SM. Induction of c-fos messenger ribonucleic acid in neuropeptide $Y$ and growth hormone $(\mathrm{GH})$-releasing factor neurons in the rat arcuate nucleus following systemic injection of the $\mathrm{GH}$ secretagogue, $\mathrm{GH}$ releasing peptide-6. Endocrinology 1997;138:771-7.

18 Shintani M, Ogawa Y, Ebihara K, et al. Ghrelin, an endogenous growth hormone secretagogue, is a novel orexigenic peptide that antagonizes leptin action through the activation of hypothalamic neuropeptide $Y / Y 1$ receptor pathway. Diabetes 2001;50:227-32.

19 Lall S, Tung LY, Ohlsson C, et al. Growth hormone (GH)-independent stimulation of adiposity by GH secretagogues. Biochem Biophys Res Commun 2001;280:132-8.
20 Sun Y, Ahmed S, Smith RG. Deletion of ghrelin impairs neither growth nor appetite. Mol Cell Biol 2003;23:7973-81.

21 Sun $Y$, Wang $P$, Zheng $H$, et al. Ghrelin stimulation of growth hormone release and appetite is mediated through the growth hormone secretagogue receptor. Proc Natl Acad Sci U S A 2004;101:4679-84.

22 Wortley KE, Anderson KD, Garcia K, et al. Genetic deletion of ghrelin does not decrease food intake but influences metabolic fuel preference. Proc Natl Acad Sci U S A 2004;101:8227-32.

23 Liedman B, Andersson H, Bosaeus I, et al. Changes in body composition after gastrectomy: results of a controlled, prospective clinical trial. World I Surg 1997;21:416-20.

24 Liedman B. Symptoms after total gastrectomy on food intake, body composition, bone metabolism, and quality of life in gastric cancer patientsis reconstruction with a reservoir worthwhile? Nutrition 1999;15:677-82.

25 Tovey FI, Hall ML, Ell PJ, et al. A review of postgastrectomy bone disease. J Gastroenterol Hepatol 1992;7:639-45.

26 Anonymous. Bone disease after gastrectomy. Br Med J 1972;1:461.

27 Anonymous. Osteomalacia after gastrectomy. Lancet 1986;1:77-8.

28 Fischer JE. Complications of surgery. In: Schwartz SI, eds. Principles of surgery, 7th edn. New York: McGraw-Hill, 1999:470-2.

29 Lehto-Axtelius D, Stenström M, Johnell O. Osteopenia after gastrectomy, fundectomy or antrectomy: an experimental study in the rat. Regul Pept 1998; 78:41-50.

30 Lehto-Axtelius D, Surve VV, Johnell O, et al. Effects of calcium deficiency and calcium supplementation on gastrectomy-induced osteopenia in the young male rat. Scand J Gastroenterol 2002;37:299-306.

31 Muhlbauer RC, Schenk RK, Chen D, et al. Morphometric analysis of gastrectomy-evoked osteopenia. Calcif Tissue Int 1998;62:323-6.

32 Ariyasu H, Takaya K, Tagami T, et al. Stomach is a major source of circulating ghrelin, and feeding state determines plasma ghrelin-like immunoreactivity levels in humans. J Clin Endocrinol Metab 2001;86:4753-8.

33 Dornonville de la Cour C, Lindström E, Norlén P, et al. Ghrelin stimulates gastric emptying but is without effect on acid secretion and gastric endocrine cells. Regul Pept 2004; 120:23-32.

34 Cummings DE, Weigle DS, Frayo RS, et al. Plasma ghrelin levels after dietinduced weight loss or gastric bypass surgery. N Engl I Med 2002;346:1623-30

35 Date Y, Murakami N, Toshinai K, et al. The role of the gastric afferent vagal nerve in ghrelin-induced feeding and growth hormone secretion in rats. Gastroenterology 2002;123:1120-8.

36 Marzullo P, Verti B, Savia G, et al. The relationship between active ghrelin levels and human obesity involves alterations in resting energy expenditure. $J$ Clin Endocrinol Metab 2004;89:936-9.

37 St-Pierre DH, Karelis AD, Cianflone K, et al. Relationship between ghrelin and energy expenditure in healthy young women. I Clin Endocrinol Metab 2004;89:5993-7.

38 Dickson SL, Leng G, Robinson IC. Systemic administration of growth hormonereleasing peptide activates hypothalamic arcuate neurons. Neuroscience 1993;53:303-6.

39 Thompson NM, Gill DA, Davies R, et al. Ghrelin and des-octanoyl ghrelin promote adipogenesis directly in vivo by a mechanism independent of the type la growth hormone secretagogue receptor. Endocrinology 2004; 145:234-42.

$40 \mathrm{Kim} \mathrm{MS}$, Yoon CY, Jang PG, et al. The mitogenic and antiapoptotic actions of ghrelin in 3T3-L1 adipocytes. Mol Endocrinol 2004;18:2291-301.

41 Salehi A, Chen D, Håkanson R, et al. Gastrectomy induces impaired insulin and glucagon secretion: evidence for a gastro-insular axis in mice. J Physiol 1999:514:579-91.

42 Salehi A, Dornonville de la Cour C, Hakanson R, et al. Effects of ghrelin on insulin and glucagon secretion: a study of isolated pancreatic islets and intact mice. Regul Pept 2004:118:143-50.

43 Surve VV, Höglund P, Håkanson R. Gastrectomized rats respond with exaggerated hypercalcemia to oral and intravenous calcium loads because of impaired ability of bone to take up Ca2+. Scand J Gastroenterol 2002:37:523-30.

44 Rumenapf G, Schwille PO, Erben RG, et al. Osteopenia following total gastrectomy in the rat-state of mineral metabolism and bone histomorphometry. Eur Surg Res 1997;29:209-21.

45 Rumenapf G, Schwille PO, Erben RG, et al. Gastric fundectomy in the rat: effects on mineral and bone metabolism, with emphasis on the gastrincalcitonin-parathyroid hormone-vitamin D axis. Calcif Tissue Int 1998;63:433-41.

46 Persson P, Gagnemo-Persson R, Chen D, et al. Gastrectomy causes bone loss in the rat: is lack of gastric acid responsible? Scand J Gastroenterol 1993;28:301-6.

47 Klinge B, Lehto-Axtelius D, Åkerman $M$, et al. Structure of calvaria after gastrectomy. An experimental study in the rat. Scand I Gastroenterol 1995;30:952-7.

48 Svensson J, Lall S, Dickson SL, et al. Effects of growth hormone and its secretagogues on bone. Endocrine 2001;14:63-6. 